\title{
Distinguishing Entailment and Presupposition Under Negation Test
}

\author{
Gatri Asti Putri Indarti \\ ELS Sanata Dharma University \\ (gatriasti@gmail.com)
}

\begin{abstract}
Distinguishing entailment from presupposition is quite difficult because their semantic relation seems to be similar. Both entailment and presupposition have an automatic relationship based on the context. However, those semantic relations can still be differentiated by using negation test to show whether a pair is entailment or presupposition. This research focuses on sentences and utterances. Thus, this research aims to analyze and test pairs of entailment and pairs of presupposition by using negation in utterances. The data were twelve comic strips from the Internet and they were analysed by using a negation test. The analysis shows that negation test is useful to test entailment and presupposition in the comic strips. It can be concluded that the difficulty of distinguishing pair of entailment and presupposition in the comic strip using negation test has been successfully solved. In this case, negation test is suitable to test entailment and presupposition. This research can be developed further by other researchers to distinguish entailment and presupposition by using another test if the negation test cannot be used to any further extent.
\end{abstract}

Keywords: entailment, presupposition, negation test, comic strips

\section{A. INTRODUCTION}

Entailment and presupposition are semantic relations that hold between sentences of a language. Both of them are related to meaning based on the notion of truth or truth-based approaches. The truth relates to the fact of the world that can be shown by a true or a false statement. On the other hand, entailment and presupposition still have different truth relations.In addition, entailment and presupposition are not easy to differentiate on some cases. They can be confusing, but both of them can be differentiated by using a negation test in which the first sentence or utterance is negated.

This paper discusses the entailment and presupposition under negation test. Entailment and presupposition are important in one's life because it requires a linguistic competence that is owned by someone. If someone states a statement, then other people can have different thoughts based on their understanding of a given statement when they interact with other people. Thus, this research focuses on the analysis of entailment and presupposition using negation test and shows whether the negation test can be used to test the difference between entailment and presupposition or not.

In this research, the researcher is interested in testing pair of utterances in the comic strips of Garfield the Cat. The researcher chooses the comic strips because they are now popular and provide interesting drawings with the writing that can give sense of humor. Therefore, the researcher hopes that this research can help people understand the difference between entailment and presupposition, especially by using negation test. 


\section{B. LITERATURE REVIEW}

Entailment and presupposition are semantic relations that are not easy to distinguish. Therefore, this section discusses the two semantic relations and the negation test used to distinguish between them. The first semantic relation is entailment. It is a relationship that applies between two sentences, where the truth of one implies the truth of the other because of the meanings of the words involved (Goddard, 1998:17). Based on Lyons (1995:117), entailment plays an important role in all theories of meaning held between sentences. The examples of entailment can be seen below.

(1) Achilles killed Hector (p)

(2) Hector died (q)

The first sentence, $p$, necessarily implies or entails the second sentence, $q$. If Achilles killed Hector, then it is necessarily that Hector died. Lyons (1995) describes that entailment is a relation between $p$ and $q$ in which $p$ and $q$ are the variables. If the truth of $q$ necessarily follows the truth of $p$ (and the falsity of $q$ necessarily follows the falsity of $p$ ), then $p$ entails $q$. The symbol for the relation of entailment is double-shafted arrow or single-shafted arrow $(\Rightarrow$ or $\rightarrow$ ). Saeed (2009) gives the composite truth table for entailment as follows.

Table 1. Composite Truth Table for Entailment

\begin{tabular}{|c|c|c|}
\hline \multicolumn{3}{|c|}{ Entailment } \\
\hline$p$ & & $q$ \\
\hline $\mathrm{T}$ & $\rightarrow$ & $\mathrm{T}$ \\
\hline $\mathrm{F}$ & $\rightarrow$ & $\mathrm{T}$ or $\mathrm{F}$ \\
\hline $\mathrm{F}$ & $\leftarrow$ & $\mathrm{F}$ \\
\hline $\mathrm{T}$ or $\mathrm{F}$ & $\leftarrow$ & $\mathrm{T}$ \\
\hline
\end{tabular}

From the table, the arrows $(\rightarrow$ and $\leftarrow)$ are to show the direction of a relation "when...then...." Then, the first line above is read "when $p$ is true, $q$ is true", and the last line is read "when $q$ is true, $p$ can be either true or false". The table also shows that only the truth of the entailing sentence or the falsity of the entailed sentence has consequences for the other sentence. When $p$ is false, $q$ can be either true or false; if people knew that Achilles killed Hector, people would not know whether Hector was dead or alive. When $q$ is true, $p$ can be either true or false; if people know that Hector is dead, that does not tell anything about whether Achilles killed him or not.

The sources of entailment are lexical and syntactic source. The example above shows lexical because there is a relationship of entailment between (1) and (2) deriving from the lexical relationship between kill and die. The meaning of kill contains the meaning of die. This can also be called as hyponymy between lexical items that can be a regular source for entailment between sentences. The other source for entailment is syntactic, in which the sentences can be in active or passive versions of the same sentence. Below are the examples of a syntactic source for the entailment.

(3) The Etruscans built this tomb.

(4) This tomb was built by the Etruscans.

The relationship of entailment gives details on paraphrase like in (3) and (4). Those sentences have the same set of entailments or they mutually entail each other (Saeed, 2009).

Furthermore, synonymy can also be expressed as entailment in terms of truth relations. The examples of synonymy are as follows.

(5) Alice owns this book.

(6) This book belongs to Alice.

From the examples, (5) is synonymous with (6) which means the same as (5) entails (6) and (6) entails (5). In addition, the truth value of (5) and (6) is the same. If the sentence in (5) is true, then (6) is also true. While, if the sentence in (5) is false, the sentence in (6) is also false. 
Contradiction is also the semantic relation that can be defined in terms of entailment. The sentence can be said as contradictories if it can entail the negation of the other (Smith and Wilson in Ja'far, 2008). The examples of contradiction are shown below.

(7) No one has led a perfect life.

(8) Someone has led a perfect life.

From the examples, whenever (7) is true, (8) must be false, and whenever (8) is true, (7) must be false.

In the entailment, if it is related to daily life, actually people do not need to check any fact in the world to deduce the entailed sentence from the entailing sentence because people have already had their own knowledge to understand the sentence relation of entailment.

The second semantic relation is presupposition. Saeed (2009) points out that presupposition means making assumption(s) of a sentenceor an utterance. Potts (2014) also adds that the presuppositions of a sentence or an utterance are the pieces of information that thespeaker assumes (or acts as if she assumes) in order to be meaningful in the current context.

Presupposition has two concepts from the two candidates; Frege and Strawson (Katz, 1973). The first concept is that a presupposition is a condition under which a sentence expressing an assertive proposition to state a truth or a falsehood. The other is that the presupposition of a sentence logically follows from the sentence and also its negation. From the two concepts, it can be understood that the concepts deal with the truth of presupposition and also the negation of the sentence.

Based on the concepts, semanticists, including Saeed (2009) can construe two approaches used in a presupposition. The first approach is from semantic point of view. Sentences are viewed as external objects and meaning is as an attribute of sentences. The semantic presupposition is related to conventional aspects of the meanings of specific words and constructions. The second approach is from the pragmatic point of view. It views sentences as the utterance of individuals engaged in communication. The pragmatic presupposition is purely speaker actions. In other words, the importance of the approaches to presupposition is to know the listener's knowledge. The examples of presupposition can be seen below.

(9) John's brother has just got back from Texas.

(10)John has a brother.

The sentence (9) presupposes the sentence (10) and it can be explained that John has a brotheris part of the assumed background of John's brother has just got back from Texas.

Table 2. Composite Truth Table for Presupposition

\begin{tabular}{|c|c|c|}
\hline \multicolumn{3}{|c|}{ Presupposition } \\
\hline$p$ & & $Q$ \\
$\mathrm{~T}$ & $\rightarrow$ & $\mathrm{T}$ \\
\hline $\mathrm{F}$ & $\rightarrow$ & $\mathrm{T}$ \\
\hline $\mathrm{T}$ or $\mathrm{F}$ & $\leftarrow$ & $\mathrm{T}$ \\
\hline
\end{tabular}

Table 2 shows that if $p$ (the presupposing sentence) is true then $q$ (the presupposed sentence) is true, but if $p$ is false, then $q$ is still true. Then, if $q$ is true, $p$ can be either true or false. From the example, it is true that John's brother has come back from Texas, and it is also true that John has a brother. If it is false that John's brother has come back from Texas, the presupposition that John has a brother still survives. Finally, if it is true that John has a brother, it does not tell anything about whether he has come back from Texas or not.

Indeed, both entailment and presupposition need knowledge to 
understand the sentence relation. Leech (1981) adds that both are types of meaningdependence held between one sentence or utterance and another. Therefore, it needs knowledge to get the idea of what the sentence means or whatsomeone says. Moreover, these two semantic relations are sometimes difficult to identify. Thus, Saeed (2009) provides a negation test in which if an entailing sentence is negated, then the entailment fails, but negating a presupposing sentence allows the presupposition to survive.

The other examples of entailment pair and presupposition pair are as follows.

(11) I saw my father today.

(12)I saw someone today.

(13) The Mayor of Liverpool is in town.

(14)There is a Mayor of Liverpool.

The relation of the sentence in (11) and (12) is as entailment. The sentence $I$ saw my father today entails the sentence I saw someone today. To make it more specific, my father entails someone. Otherwise, the relation of the sentences in (13) and (14) is as presupposition. The sentence (13) presupposes the sentence (14) and it can be explained that There is a Mayor of Liverpool is part of the assumed background of The Mayor of Liverpool is in town.

To prove that they are the entailment pair or presupposition pair, firstly the entailing sentence in (11) and the presupposing sentence in (13) above are negated as follows.

(15) I didn't see my father today.

(16) The Mayor of Liverpool isn't in town.

The entailing sentence in (11) that is negated in (15) no longer entails (12) and sentence in (12) no longer automatically follows from the preceding sentence or probably it is true. On the other hand, the presupposing sentence in (13) that is negated in (15) still has the presupposition. Thus, negating the entailing sentence destroys entailment, whereas, negating the presupposing sentence does not affect the presupposition. In addition, Burton-Roberts in Carston (1998)considers that a negation operator does not cancel presuppositions.

It can be concluded that the aim of the truth of entailment and presupposition is to know the meaning of a sentence and to know the conditions under which that sentence is true. Moreover, in relation to the truth, negation test can be used to test those semantic relations. Tremper and Frank (2013) assume that the negation test can help to distinguish the closely related verb relations of a sentence or utterance.

\section{METHODOLOGY}

This research concerns with the semantic field. It is to describe the nature of entailment and presupposition under negation test in sentences and utterances. The comic strips of Garfield the Cat became the data of this research. The researcher found some sources in some books, articles and other sources to support the analysis. The researcher collected the data from the Internet in http://reallifeglobal.com/ learn-english-comic-strips-garfield/, on May 4th, 2015. After collecting the data, the researcher analysed the twelve comic strips. To analyse the data, the researcher used a negation test for the entailing utterances and the presupposing utterances. Then, the researcher got the result showing they were included either entailment or presupposition, gave the analysis, and drew conclusion.

\section{FINDINGS AND DISCUSSION}

The discussion focuses on the entailment and presupposition in comic strips of Garfield the Cat. The characters are Garfield (the cat), Jon as the owner, and Odie 
(the dog). The comic strips and the utterances produced by each speaker are shown below.

1. (a) Frankly, I don't know how you can eat cat food.

(b) Like this.

The context of the first comic strip describes that Jon is curious to know how Garfield eats food. It can be assumed that Jon wants to know whether Garfield has the same characteristic as the other animals or has different way to eat cat food. Garfield looks annoyed with Jon and Garfield shows him the way of eating cat food. When Jon knows that Garfield takes the food and eats it like a man, Jon is very surprised to see it.

The first comic strip shows that when the first utterance is negated, then the negative sentence becomes positive. Thus, the sentence becomes Frankly, I know how you can eat cat food. If it is related to the second utterance, then the new utterance is still related to the utterance Like this. Whether the owner of the dog knows or does not know is not the problem since the fact in 1 (b) still shows the way how Garfield eats cat food. Thus, the first comic strip is called presupposition.

2. (a) How'd you like to be a bear, Garfield?

(b) Don't be ridiculous.

In the second comic strip, Jon thinks that Garfield has the same character as a bear, then Jon offers Garfield to become a bear since Garfield likes to sleep a lot. Garfield thinks that Jon is making a joke and Garfield answers that it is ridiculous because Garfield is a cat and cannot become a bear. A few minutes later, Garfield starts to sleep and Jon just looks at Garfield, but Jon is not surprised at it anymore.

The second comic strip is described as presupposition. The first utterance can be negated into How wouldn't you like to be a bear, Garfield?. The negated utterance does not affect Garfield's statement in Don't be ridiculous. In relation to the negated utterance, it means that Garfield is a cat and indeed, he is not a bear. Then, it can still be true if Garfield states Don't be ridiculous. Thus, this is called presupposition.

3. (a) I'm going shopping.

(b) Hand over your man card.

The third comic strip is understood that Jon really wants to go shopping, but Garfield asks him first to give his man card. Garfield's statement shows a joke. When Garfield asks the man card means that Jon is not a man since the men commonly do not have the activity of shopping. It can be stated that if a man acts like a woman, people can jokingly ask for the man card, implying that they are no longer a man.

The third is entailment. The utterance in 3 (a) can be negated into I'm not going shopping. Then, if the utterance in 3 (b) is related to the negated utterance, it affects the utterance in 3 (b). When a man wants to go shopping, his friend can ask for the man card, but if the man does not want to go shopping, his friend cannot ask him for the man card since he does not have intention to go shopping like a woman. Then, this pair of utterance can be called entailment.

4. (a) I want you to lose weight, and I mean now!

(b) Yes, Sir.

The context of the fourth comic strip explains that Jon wants Garfield to lose weight. Jon thinks that Garfield weighs too much and Garfield's response is only by saying yes showing that Garfield agrees with Jon.

The first utterance of the fourth comic strip becomes I don't want you to lose weight, and I don't mean now as the negated utterances. If it is related to 4 (b), the negated utterance is still accepted. When the first 
speaker says I don't want or I want, it is not affected Yes, Sir as the second utterance. Therefore, the utterance in 4 is named presupposition.

5. (a) Looking forward to dinner?

(b) How can you tell?

The comic strip in 5, Jon knows that Garfield is waiting for dinner. Garfield's expression shows that he really needs food for dinner. Then Jon makes sure Garfield by asking whether he is looking forward to dinner or not and Garfield feels annoyed of Jon's question. From Garfield's response, Garfield seems angry to Jon because Jon does not provide anything to eat or drink.

The utterance in 5 can be described as presupposition. When the first utterance in 5 (a) is negated into Not looking forward to dinner?, the negated utterance can still be related to the second utterance in How can you tell?. The first speaker makes sure that the second speaker does not look forward to dinner and the second speaker can still respond How can you tell? because it can be assumed that the first speaker knows the feeling of the second speaker. Thus, the utterance in 5 can be said as presupposition since the negated utterance does not affect the second utterance in 5 (b).

6. (a) I think maybe you should cut down on the snacks, Garfield.

(b) We're being a bit over reactive, aren't we?

The context of the sixth comic strip can be described that both Jon and Garfield act over reactive since Garfield has run out of something and he acts too much, and Jon thinks that Garfield needs to cut down on the snacks since Garfield eats up the food stock.

The comic strip in 6 is described as entailment. It is known that if the first utterance is negated into I don't think maybe you should cut down on the snacks, Garfield, then this negated utterance does not relate to the second utterance anymore because there is no expression showing the excessive act or overreaction in a negated utterance. Therefore, the utterance in 6 is called entailment.

7. (a) I just heard a joke.

(b) Ha! Ha! Ha! Ha! Ha! Ha! Ha! Ha!

In this comic strip, Jon has just got a joke and he intends to tell Garfield about it, but before telling the joke, Garfield laughs as if Jon has told him about the joke. Jon thinks that Garfield probably is foolish, but Garfield thinks that it may be funny since when Jon says the word a joke, spontaneously Garfield laughs. It can be assumed that a joke is something funny that can make people laugh. Therefore, Garfield laughs first before Jon explains the joke to him.

The seventh comic strip shows entailment. If it is tested, the first utterance can be negated into I just did not hear a joke. Then, if it is related to the second utterance, it becomes strange to laugh since the first speaker does not have a joke and it is impossible to use Ha! Ha! Ha! Ha! Ha! Ha! Ha! $H a !$ as a reply. The second utterance is not appropriate for the negated utterance. Thus, the utterance in 7 is called entailment.

8. (a) They built a hotel on it (the meadow).

(b) You could hang out in the lobby.

The context of this comic strip shows that Jon wants to enjoy his day in the meadow. Unfortunately, he goes back with full of the disappointment. He cannot find the meadow because the constructors build a hotel on it. Garfield thinks and suggests Jon to hang out in the lobby as a good solution.

The comic strip in 8 shows that it is presupposition because when the first utterance is negated becoming They did not build a hotel on it (the meadow), it still becomes a part of the second utterance in which the word you as the first speaker can 
still hang out in the lobby. Then, there is no problem whether people build a hotel or not. It has no effect on the second utterance in 8 (b).

9. (a) I hate Mondays.

(b) This is your conscience speaking. It's not nice to hate Mondays. Look at it as starting a fresh

week with a clean slate.

In this comic strip, it is clearly described that Garfield hates Mondays. He is too lazy doing activities on Mondays. The clock gives Garfield spirit and convinces Garfield that doing activities on Mondays can become a fresh week to start his day. However, Garfield is still lazy and does not care about what the clock says.

The utterance in 9 (a) is tested by negating it into I don't hate Mondays. The negated utterance is tested and related to the second one in 9 (b). The second utterance in 9 (b) can be divided into three points of utterance; This is your conscience speaking, It's not nice to hate Mondays, and Look at it as starting a fresh week with a clean slate. If the first point of utterance is related to the negated utterance, then it still has a relation between I don't hate Mondays and This is your conscience speaking. It does not affect whether Garfield hates Mondays or likes Mondays because it is a matter of conscience. Therefore, for the first point is described as presupposition. Then, if the negated utterance Idon't hate Mondays is related to the second point of utterance It's not nice to hate Mondays, it can be still called presupposition since both of the utterances has the same meaning. The meaning is that someone likes Mondays. The third point of utterance in Look at it as starting a fresh week with a clean slate can also be the presupposition of the first utterance I don't hate Mondays. It shows that when someone likes Mondays, it means that he/she has to think positively as a fresh week. Thus, the relation of 9 (a) and 9 (b) is named presupposition.

10. (a) Perfect!

(b) Ah, technology.

The comic strip in 10 gives details that Jon calls a friend and the problem arises. Jon gets difficulty in catching the voice of his friend on the telephone. It probably has no signal. Then he finds a way to make the voice clear by changing his position upside down. In other words, Jon finds the way out to solve the problem in order to make it perfect. Garfield just considers it as a matter of technology that occasionally can make people crazy because of it.

This comic strip shows presupposition because when the utterance in 10 (a) is negated into Not perfect!, it does not affect the second utterance. No matter what Jon says Perfect! or Not perfect!, Garfield's utterance is still acceptable. In relation to the second utterance, if Jon says Not perfect, then it also means that the technology can result any kind of problem.

11. (a) Trying to figure life out makes my head hurt.

(b) Try having nine of them to figure out, pal.

In this comic strip, Jon grumbles about his life and he tries to figure life out but once he thinks about it, he has got a pain in his head. Garfield seems relaxed and comments on Jon's statement. Garfield thinks that a life of a man has the same as a life of a cat. Since a cat has nine lives, Garfield asks Jon to find nine of them to figure life out. Garfield's statement makes Jon feel annoyed because Garfield does not know what actually a life is and how to deal with it.

The eleventh comic strip is described as presupposition. The utterance in 11 (a) is negated into Trying to figure life out does not make my head hurt. This negated utterance 
still has relation to the second utterance in Try having nine of them to figure out, pal. It can be stated that when Jon tries to figure life out and his head becomes hurt or not, it does not affect the second utterance. When Garfield asks Jon to try having nine of them to figure life out, it can be still related to the negated utterance. The utterance trying to figure life out does not make Jon's head hurt shows that Garfield still can ask Jon to try having nine of them to figure out. Then, this is called presupposition.

12. (a) Make a wish!

(b) Like that ever works.

The context of the last comic strip describes that Garfield has his birthday. Jon and Odie give a surprise by bringing him a birthday cake and ask him to make a wish. Garfield thinks that it is impossible to happen after making a wish. He is not sure that his wish can be true. A few moments later, someone is ringing the bell and all of them are questioning, especially Garfield. He thinks that possibly his wish may be true after making a simple wish.

The last comic strip shows entailment since when 12 (a) is negated becoming Don't make $a$ wish, the second utterance affects the first utterance. It can be explained that when Jon, the owner of Garfield, asks Garfield to make a wish, the utterance like that ever works makes sense of the first utterance. While, when Jon asks Garfield not to make a wish, the second utterance like that ever works is not quite good to support the first utterance. The first utterance can affect 12 (b). Thus, it is described as entailment.

The analysis in comic strips of Garfield the Cat is found that number 3, 6, 7 and 12 are entailment and number 1, 2, 4, 5, 8, 9, 10 , and 11 are presupposition. Therefore, from the analysis, the researcher has tested that negation test is helpful to distinguish a pair of entailment and presupposition in the exercises and the comic strips.

\section{E. CONCLUSION}

To sum up, assuming something can be confusing for people who are the second speaker because they have different ideas. Occasionally people as the second speaker can have a little misunderstanding because they do not share the same idea as the first speaker. Therefore, they need to know the truth of something written or uttered as in entailment and presupposition and is necessary to understand the difference between the semantic relations between them.

The difference between those two semantic relations can be proved by using a negation test. When an entailing sentence is negated, it cannot entail the following statement or sentence. However, when a presupposing sentence is negated, it still follows the following statement or sentence. These semantic relations hold between sentences of a language. Thus, differentiating between those two semantic relations is important for people in order to understand a language by assuming the statement properly.

In this research, the researcher found some pairs of entailment and some pairs of presupposition in the comic strips. In the comic strips, there are eight pairs of presupposition and four pairs of entailment. Based on the analysis, the researcher has successfully distinguished pair of entailment and presupposition.

For further research, it is expected that other researchers can conduct better research related to the test used to show pair of entailmentand pair of presupposition using different data. If the negation test cannot be used to test entailment and presupposition, then another test can be applied.

\section{REFERENCES}

Carston, Robyn. (1998). Negation, 'presupposition' and the semantics/ pragmatics distinction. Cambridge: 
Cambridge University Press: 309-350. Journal of Linguistics, Vol. 34, No. 2, September 1998. Available at http:// www.jstor.org/stable/4176477 (May 25th, 2015).

Goddard, Cliff. (1998). Semantic Analysis: A Practical Introduction. Oxford: Oxford University Press.

Hurford et.al. (2007). Semantics: A Coursebook. Cambridge: Cambridge University Press.

Ja'far, Areej As'ad. (2008). Entailment and Presupposition. Babylon University: 7.Available at http://www. uobabylon.edu.iq/uobColeges / fileshare/articles/Entailment\%20 \&\%20Presupposition.pdf(May 25th, 2015).

Katz, Jerrold J. (1973). On Defining "Presupposition". The MIT Press: 256260. Linguistic Inquiry, Vol. 4, No. 2, 1973. Available at http://www.jstor. org/stable/4177770 (May 25th, 2015).

Leech, Geoffrey. (1981). Semantics: The Study of Meaning(Second edition - revised and updated). Harmondsworth: Penguin.
Lyons, John. (1995). Linguistic Semantics: An Introduction. Cambridge: Cambridge University Press.

Potts, Christopher. (2014). Handbook:Presupposition and Implicature. Stanford Linguistics: 3. Available at http://web.stanford. edu/ cgpotts/manuscripts/pottsblackwellsemantics.pdf(May 25th, 2015).

Saeed, John. I. (2009). Semantics (Third edition). The United Kingdom: WilleyBlackwell.

Tremper, Galina, and Anette Frank. (2013). A Discriminative Analysis of FineGrained Semantic Relations including Presupposition: Annotation and Classification. Dialogue \& Discourse, Vol 4, No. 2, 2013. Available at http:// elanguage.net/journals/dad/article/ download/2892/3584 (May 25th, 2015)

---. (2012). Learn English with Comic Strips Garfield the Cat. Available at http:// reallifeglobal.com/learn-englishcomic-strips-garfield/(May 4th, 2015). 


\section{Appendices}

1

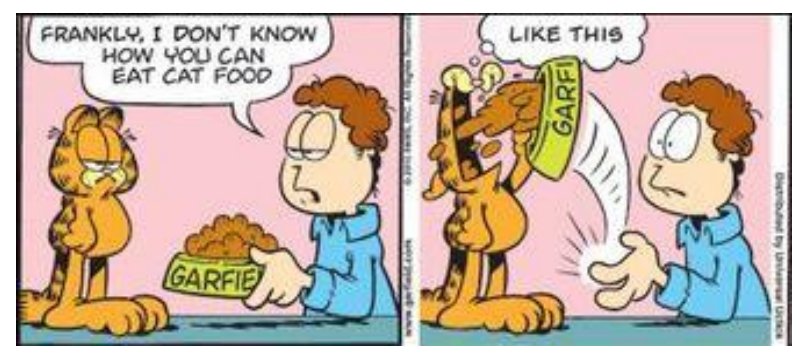

2

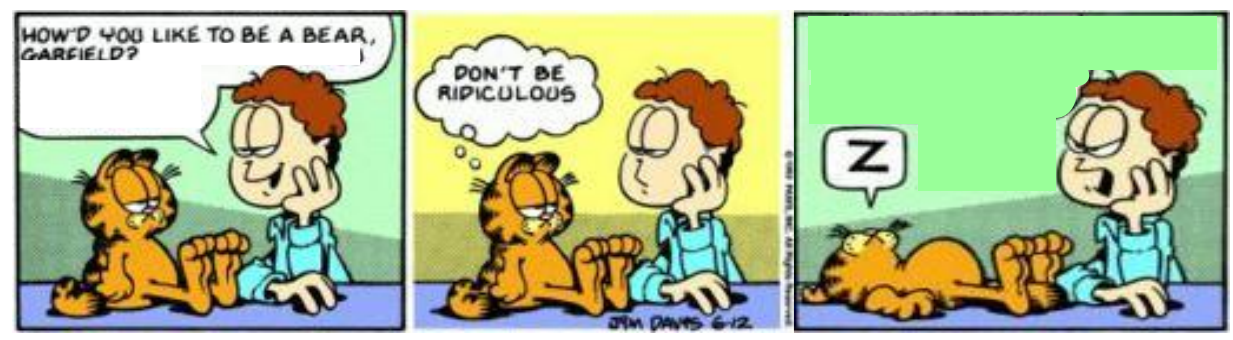

3



4

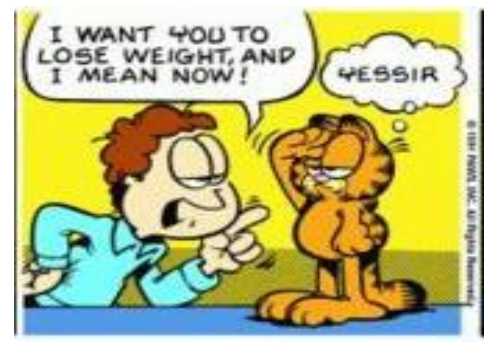

5

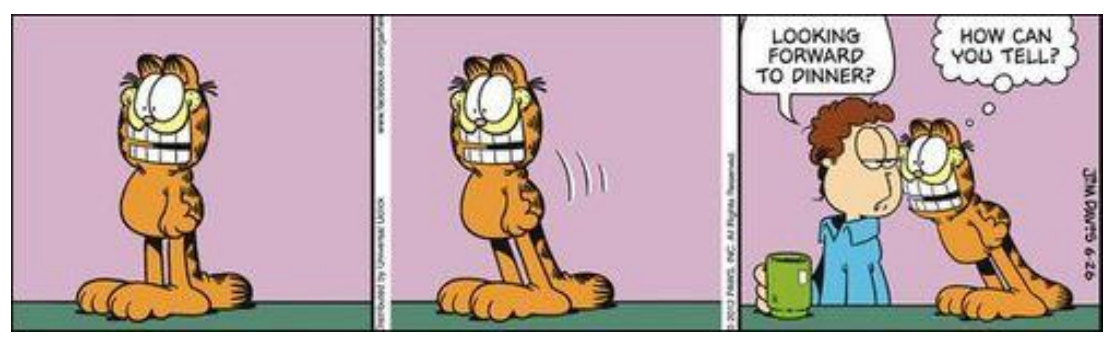

6

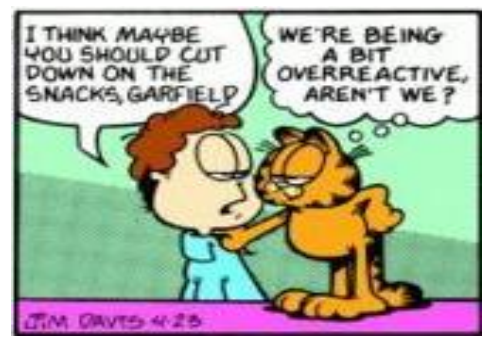


7

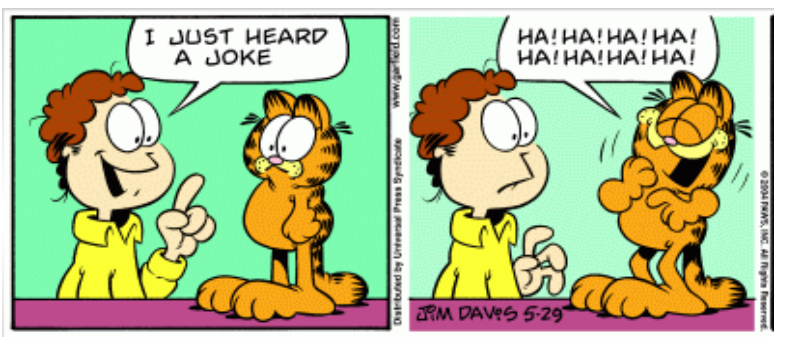

8

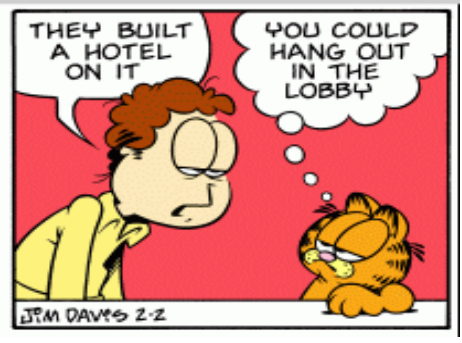

9

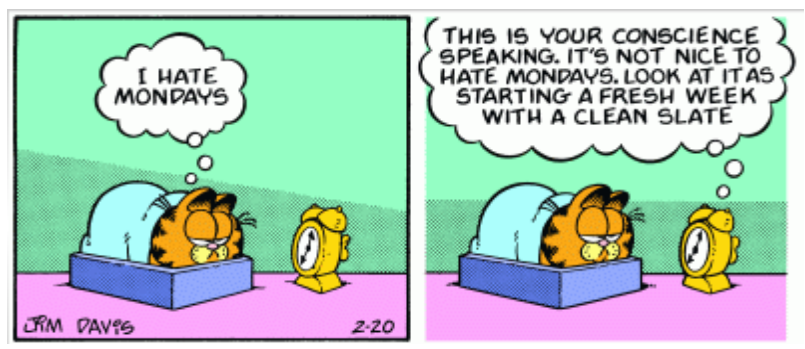

10

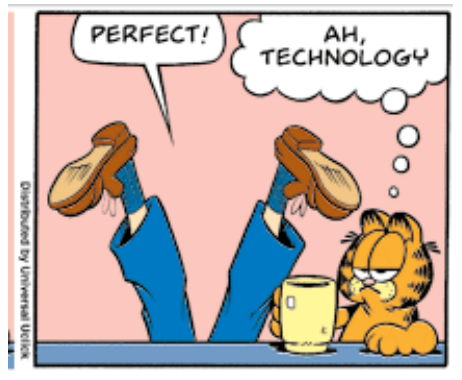

11
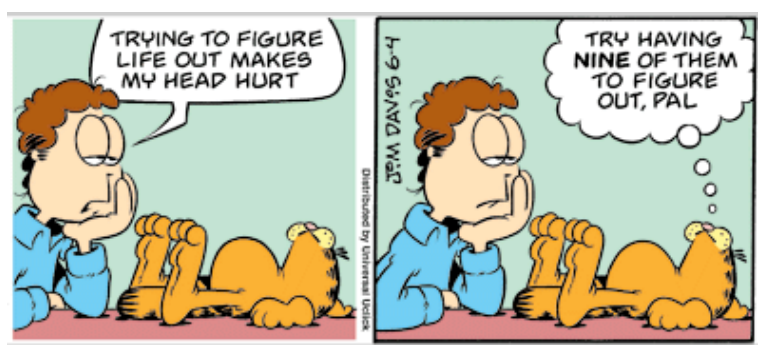

12

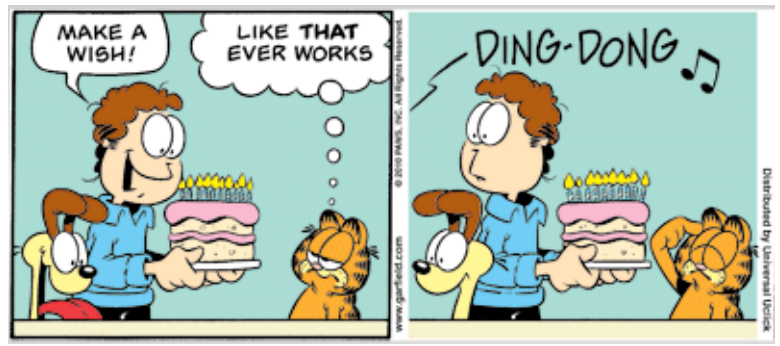


